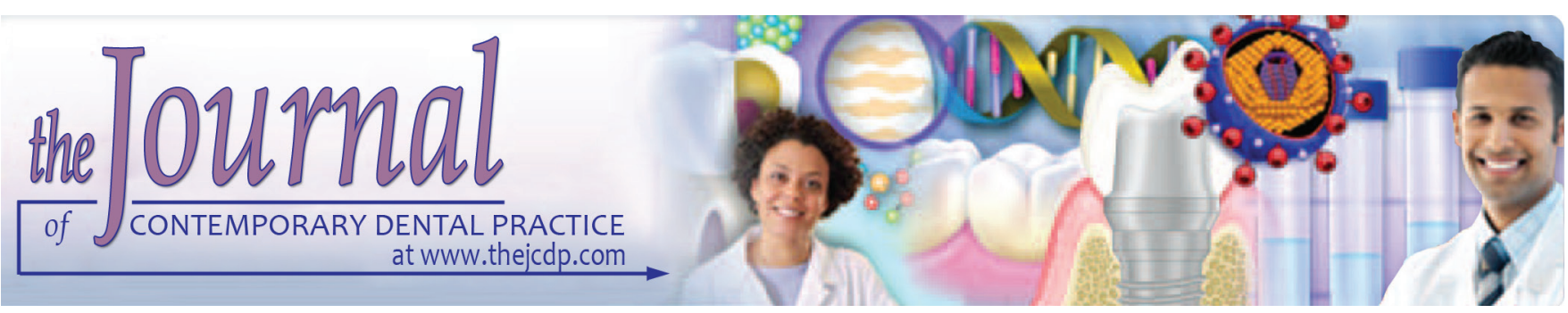

\title{
Antimicrobial and Cytotoxic Activity of Cinnamomum zeylanicum, Calcium Hydroxide, and Triple Antibiotic Paste as Root Canal Dressing Materials
}

\footnotetext{
${ }^{1}$ Abbas Abbaszadegan, ${ }^{2}$ Sahar Dadolahi, ${ }^{3}$ Ahmad Gholami, ${ }^{4}$ Mahmoud Reza Moein

${ }^{5}$ Shahram Hamedani, ${ }^{6}$ Younes Ghasemi, ${ }^{7}$ Paul Vincent Abbott
}

\begin{abstract}
Objective: The aim of this article was (i) to define the chemical constituents of Cinnamomum zeylanicum essential oil (CEO), (ii) to compare the antimicrobial activity of CEO with triple antibiotic paste (TAP) and calcium hydroxide $\left[\mathrm{Ca}(\mathrm{OH})_{2}\right]$ on planktonic and biofilm Enterococcus faecalis; and (iii) to compare the cytotoxicity of these medicaments on L929 fibroblasts.

Materials and methods: Gas chromatography-mass spectrometry was used to define the constituents of CEO. Zone of inhibition, minimum inhibitory concentration (MIC), minimum bactericidal concentration (MBC), and time-kill tests were performed. Further, 108 human teeth were infected with E. faecalis and treated with the medicaments for 1,7 , and 14 days. Cytotoxicity was assessed by exposing L929 fibroblasts to the medicaments.
\end{abstract}

Results: Cinnamaldehyde was the main component of CEO. Triple antibiotic paste had the greatest zone of inhibition and the smallest MIC and MBC. Triple antibiotic paste and CEO eradicated planktonic E. faecalis after 4 and 24 hours, while $\mathrm{Ca}(\mathrm{OH})_{2}$ failed to achieve $100 \%$ killing after 24 hours.

\footnotetext{
${ }^{1}$ Department of Endodontics, School of Dentistry, Shiraz University of Medical Sciences, Fars, Islamic Republic of Iran

'Students' Research Committee, School of Dentistry International Branch, Shiraz University of Medical Sciences Fars, Islamic Republic of Iran

${ }^{3,6}$ Pharmaceutical Sciences Research Center and Department of Pharmaceutical Biotechnology, School of Pharmacy, Shiraz University of Medical Sciences, Fars, Islamic Republic of Iran

${ }^{4}$ Medicinal Plants Processing Research Center, Shiraz University of Medical Sciences, Fars, Islamic Republic of Iran

${ }^{5}$ Private practice, Fars, Islamic Republic of Iran

${ }^{7}$ School of Dentistry, University of Western Australia, Australia

Corresponding Author: Ahmad Gholami, Assistant Professor Pharmaceutical Sciences Research Center, Shiraz University of Medical Sciences, Fars, Islamic Republic of Iran, Phone: +989173140518, e-mail: gholami@sums.ac.ir
}

Cinnamomum zeylanicum essential oil and TAP eradicated biofilm $E$. faecalis after 7 and 14 days, but $\mathrm{Ca}(\mathrm{OH})_{2}$ could not eliminate $E$. faecalis after 14 days. Cinnamomum zeylanicum essential oil was the most biocompatible medicament.

Conclusion: Cinnamomum zeylanicum essential oil is an efficient antibacterial agent against planktonic and biofilm E. faecalis and it was cytocompatible to L929 fibroblasts. Therefore, CEO has the potential to be used as an antimicrobial agent in root canal treatment.

Keywords: Antimicrobial agents, Cytocompatibility, Root canal medicaments, 3Mix ointment.

How to cite this article: Abbaszadegan A, Dadolahi S, Gholami A, Moein MR, Hamedani S, Ghasemi Y, Abbott PV. Antimicrobial and Cytotoxic Activity of Cinnamomum zeylanicum, Calcium Hydroxide, and Triple Antibiotic Paste as Root Canal Dressing Materials. J Contemp Dent Pract 2016;17(2):105-113.

Source of support: Nil

Conflict of interest: None

\section{INTRODUCTION}

Medicinal plants have been found to have many valuable applications in various fields, such as medicine, pharmaceutics, cosmetic, agriculture, and food industries. ${ }^{1}$ Medicinal herbs have also been reported to be efficient in the treatment of infectious diseases while evading many of the side effects related to synthetic antimicrobials. ${ }^{2}$

The antimicrobial activity of some herbs, such as Arctium lappa, ${ }^{3}$ Morinda citrifolia, ${ }^{4}$ triphala, green tea polyphenols, ${ }^{5}$ liquorice, ${ }^{6}$ Syzygium aromaticum, Ocimum sanctum, and Cinnamomum zeylanicum, ${ }^{7}$ Aloe vera, Zataria multiflora, ${ }^{8}$ Myrtus communis, ${ }^{9}$ Ferula Gummosa ${ }^{10}$ and Cuminum Cyminum ${ }^{11}$ has been evaluated against Enterococcus faecalis in contemporary endodontic studies.

Cinnamomum zeylanicum also known as Ceylon Cinnamon or True Cinnamon is one of the medicinal herbs from the Lauraceae family, famous for its antimicrobial, anti-inflammatory, and analgesic properties. ${ }^{12}$ This plant 
is endemic to the forests of Eastern and Southeastern Asia and Australia, ${ }^{13}$ and it has the essential approval to use in food and medical industries from the World Health Organization, United States Food and Drug Administration and Australia's Therapeutic Goods Administration.

The chemical composition of C. zeylanicum essential oil (CEO) can fluctuate extensively due to the diversity in the time and location of the sample collection and the method of essential oil extraction. ${ }^{14}$ Cinnamomum zeylanicum essential oil is yellow-colored oil with a delicate aroma and sweet pungent taste. It has a specific gravity of 1.010-1.030 and is soluble in $70 \%$ alcohol. Volatile components present in CEO can generally be classified into monoterpenes, sesquiterpenes, and phenylpropenes. ${ }^{15}$

The antimicrobial activity of C. zeylanicum is attributed to its essential oils, such as cinnamaldehyde. ${ }^{16}$ Cinnamomum zeylanicum is biocompatible ${ }^{17}$ and effective against many microorganism species including E. faecalis. ${ }^{18,19}$

In a recent study, Gupta et $\mathrm{al}^{7}$ reported that the extract of C. zeylanicum could completely inhibit the growth of biofilm E. faecalis after 12 hours, and thus proposed this herb to be used as an intracanal medicament. Therefore, it is relevant to further investigate the benefits of this medicinal plant, particularly concerning its biological activity as a root canal dressing material.

This study was, therefore, designed and performed in two phases to investigate the potential of using $C$. zeylanicum as a root canal dressing material. In the first part of this study, the aim was to define the chemical composition of CEO to elude the absence of standardization and to provide a better understanding of its bioactivity. In the second part of this study, the antibacterial activity of $\mathrm{CEO}, \mathrm{Ca}(\mathrm{OH})_{2}$, and TAP was evaluated and compared against planktonic and biofilm $E$. faecalis. The cytotoxicity of each material was also assessed against L929 mouse fibroblasts. The hypothesis was that the bactericidal activity and cytotoxicity of $\mathrm{CEO}, \mathrm{Ca}(\mathrm{OH})_{2}$, and TAP are similar.

\section{MATERIALS AND METHODS}

\section{Isolation and Analysis of the Essential Oil}

Ethics Committee of Shiraz University of Medical Sciences reviewed the study and approved its protocol (\# 8692008). Cinnamomum zeylanicum barks were purchased from a local medicinal plant store in Shiraz and then identified and authenticated by Ms S Khademiann, an expert plant taxonomist, based on morphological depiction and regarding the known samples that have been previously collected. The voucher specimen (pm 666) of the plant was kept at the Herbarium of the Department of Pharmacognosy, Shiraz School of Pharmacy. Plants were washed and stored in a sheltered place for
20 days at room temperature and air-dried. To provide the pertinent form of the C. zeylanicum, a blender ground the plants to produce a fine powder. To provide the essential oil, $300 \mathrm{gm}$ of this powder was steam distillated by using a clevenger-type apparatus (yield: 0.93\% \pm 0.23 ). The organic layer was parted, then concentrated under pressure, dried over anhydrous sodium sulfate $(2.5 \mathrm{mg} /$ $\mathrm{ml}$ concentration), and finally stored in sealed vials at low temperature $\left(4^{\circ} \mathrm{C}\right)$. Gas chromatography-mass spectrometry (GC-MS) analysis was performed by using Agilent 7890 gas chromatograph with a mass detector (Agilent technologies model 5975 C, California, USA). The gas chromatograph was also provided with a HP-5MS capillary column (phenyl methyl siloxane, $30 \mathrm{~m} \times 0.25 \mathrm{~mm}$ internal diameter, Agilent Technologies). The ingredients were detected by using Kováts retention indices, benefiting from a literature database and by comparing their mass spectra with the Wiley library. The relative percentage values were deliberated by calculating the total area under the peaks using the apparatus software.

\section{Preparation of the Medicaments}

All stages of the experiments were performed under strict aseptic conditions. The essential oil was mixed with polyethylene glycol (PEG 400, Quimimax Comércio e Indústria Ltda., Campinas, SP, Brazil) as a vehicle in the ratio of 3:2 (wt/vol). The $\mathrm{Ca}(\mathrm{OH})_{2}$ powder (Henry Schein Company, Melville, New York, USA) was also mixed with PEG 400 in powder to liquid ratio of 3:2 (wt/vol) to obtain paste-like consistency. It is notable that PEG is frequently used as a vehicle in root canal medicaments and provides many ultimate properties including very low toxicity, excellent solubility in aqueous solutions, as well as extremely low immunogenicity and antigenicity. ${ }^{20}$ The TAP was prepared by combining Ciprofloxacin 200 (mg), Metronidazole 500 (mg), and Minocycline 100 (mg) in equal amounts (vol) of 1:1:1. The resultant powder was mixed with PEG 400 (3:2 wt/vol). The final concentration of all medicaments was $1.5 \mathrm{mg} / \mathrm{ml}$.

\section{Measurement of Antibacterial Activity against Planktonic E. faecalis}

In this stage, all procedures were carried out according to the guidelines of the Clinical and Laboratory Standards Institute $^{21}$ for the primary evaluation of experimental medicaments in terms of their antibacterial susceptibility against E. faecalis (ATCC 29212). Briefly, for disk diffusion assay, the bacterial culture was adjusted to $0.5 \mathrm{McF}$ arland standard $\left[1.5 \times 10^{8}\right.$ colony forming units $(\mathrm{CFU} / \mathrm{ml})$, in an optical density of $600 \mathrm{~nm}$ ] and a sterile swab was used to add this culture to Mueller-Hinton agar plates. Then the paper disks which had been soaked in and saturated 
with the experimental medicaments, ampicillin (positive control), and sterile water (negative control) were located on the surface of Mueller-Hinton agar. The PEG 400 was also tested as an experimental group. After incubation for 24 hours at $37^{\circ} \mathrm{C}$, the plates were assessed for presence of inhibition zones. All assays were performed in six replicates.

The microdilution broth method was applied to determine the minimum inhibitory concentrations (MICs) of the testing medicaments. In short, 10-fold serial dilutions down to $10^{-4}(1: 1,1: 10,1: 100,1: 1000,1: 10000)$ of the testing and control groups were provided with Mueller-Hinton broth in 96-well microplates. Later, the bacterial suspension (0.5 McFarland Standard) was appended to them in a way that the concentration of the medicaments was $1 \mathrm{mg} / \mathrm{ml}$ in the first wells. The plates were incubated for 24 hours at $37^{\circ} \mathrm{C}$. Ampicillin was regarded as the positive control and normal saline was the negative control. The tests were carried out in triplicate.

To quantify the minimum bactericidal concentrations (MBCs), those media from wells which had no bacterial growth were cultured on tryptic soy agar. The MBC value was considered as the lowest concentration which could kill $98 \%$ the microorganisms in the primary inoculums so that less than four visible colonies could be detected after 24 hours incubation at $37^{\circ} \mathrm{C}$ in agar plates.

To assess the killing activity of the medicaments during different time intervals, the overnight grown culture of E. faecalis was centrifuged at $2500 \mathrm{rpm}$ for 10 minutes then washed with phosphate buffer saline and suspended in brain heart infusion (BHI; Himedia Laboratories, Mumbai, India) medium. The prepared concentrations of the medicaments and a control group (sterile water) were incubated with an adjusted amount of the bacteria equal to a $0.5 \mathrm{McF}$ arland standard in $\mathrm{BHI}$ medium in 96-well round bottom plates in such a way that the concentration of the medicaments was $1 \mathrm{mg} / \mathrm{ml}$. The bacteria were harvested at 1, 4, and 24 hours after incubation and 10-fold serial dilutions were made down to $10^{-4}$. Then, $20 \mu \mathrm{l}$ of each dilution was plated on $\mathrm{BHI}$ agar plates. After 24 hours incubation, the number of CFUs was counted and the bacterial growth was measured by the CFU/ml counts of E. faecalis according to the known dilution factor. Microscopic observation of the colonies was performed to rule out any contamination. All procedures were performed in triplicate.

\section{Measurement of Antibacterial Activity against Biofilm E. faecalis in Contaminated Root Canals}

A total of 108 extracted intact human permanent mandibular premolar teeth with straight root canals and mature apices were included in this phase of study. These teeth had no caries or fractures. They were stored in distilled water until the commencement of the experiment to avoid possible dehydration. All teeth were decoronated from 2 to $3 \mathrm{~mm}$ below the cementoenamel junction under water coolant, using a safe-sided diamond disk, and root lengths were standardized to $15 \mathrm{~mm}$. To measure the working lengths (WLs) of the canals, a K-file \# 15 (Dentsply, Maillefer, Ballaigues, Switzerland) was introduced to each canal until it was apparent at the apical foramen, and then this length was measured and $1 \mathrm{~mm}$ was reduced from this value to obtain WL. The root canals were prepared to the WL by ProTaper rotary system (Dentsply, Maillefer Tulsa, Ok, USA) succeeding to file \# F3. The root canals were irrigated with $2.5 \% \mathrm{NaOCl}$ (Vista Dental Products, Racine, WI, USA) between each instrument change. Then, the root canals were irrigated with $17 \%$ ethylenediamine tetraacetic acid (EDTA; Vista Dental Products, Racine, WI, USA) for 5 minutes and subsequently with $5.25 \% \mathrm{NaOCl}$ for 5 minutes to remove smear layer. The enlarged apical foramen was closed with composite resin, and the external root surfaces were sealed with nail polish, except for the coronal access cavity. The samples were mounted and fixed in 96-well cell culture microplates using acrylic resin. The testing specimens $(n=10$ in each group) were randomly allocated into nine 96-well cell culture microplates (Corning Incorporated, Corning, NY, USA) and also six control microplates ( $\mathrm{n}=3$ in each group). Then, they were sterilized by ethylene oxide (Acecil, Campinas, São Paulo, Brazil). To check the sterilization efficiency, root canals were filled with BHI medium. Then they were kept in an incubator (Mart Microbiology BV, the Netherlands) for 48 hours at $95 \%$ relative humidity and $37^{\circ} \mathrm{C}$, and microbial assessments were performed on samples taken from each root canal.

Inoculation of the root specimens was performed under a laminar flow chamber. The isolated 48-hour colonies of pure culture of E. faecalis, cultivated on BHI agar plates, were conceded in $5 \mathrm{ml}$ BHI broth media and adjusted to reach a spectrophotometric turbidity of $1.5 \times$ $10^{8} \mathrm{CFU} / \mathrm{ml}$. Under a laminar air-flow cabinet, the root samples were contaminated with $10 \mu$ inoculums of E. faecalis and incubated at $37^{\circ} \mathrm{C}$ for 21 days. For continuous bacterial feeding, the root canals (except for the negative control groups) received $\mathrm{BHI}$ on alternate days by using $0.5-\mathrm{ml}$ insulin syringes throughout this period. To evaluate the pureness of the bacterial culture, gram staining and catalase reaction assessments were implemented.

The primary microbial assessment was performed after 3 weeks. This was done by flooding the canal with sterile saline, followed by placing a size 30 Hedström file into the canal to scrape the dentin during the process. Then three sterile paper points (Gapadent Co. Ltd., Korea) were placed in each canal for 1 minute. The contaminated paper points were removed from the canals under laminar flow 
and were conveyed into tubes containing $1 \mathrm{ml}$ of $\mathrm{BHI}$. The tubes were vortexed for 1 minute and the resultant solution was successively diluted 10-fold in BHI broth. Aliquots of $100 \mu \mathrm{l}$ from the suspension were smeared on BHI agar plates and then incubated at $37^{\circ} \mathrm{C}$ for 24 hours. Bacterial growth was then deliberated by the $\mathrm{CFU} / \mathrm{ml}$ counts of E. faecalis and approved by colony morphology and gram stain. The root canals were reprepared using $5 \mathrm{ml}$ of sterile saline solution, then filled with 17\% EDTA for 3 minutes. Ultimate irrigation of canals was done with sterile saline solution. The root canals were then dried by using sterile paper points and were filled with the intracanal medicaments as will be described below. The microplates containing the roots were randomly allocated into the following experimental groups regarding the applied medicaments and their intracanal contact time:

- Groups 1, 2, and 3 ( $\mathrm{n}=10$ in each group): CEO-1, 7, and 14 days.

- Groups 4, 5, and 6 ( $\mathrm{n}=10$ in each group): TAP - 1, 7, and 14 days.

- Groups 7,8, and 9 ( $\mathrm{n}=10$ in each group): $\mathrm{Ca}(\mathrm{OH})_{2}-1$, 7 , and 14 days.

- Groups 10,11, and 12 as positive control groups ( $\mathrm{n}=3$ in each group): Sterile saline-1, 7, and 14 days.

- Groups 13,14, and 15 as negative control groups ( $n=3$ in each group): Not any bacterial contamination-1, 7 , and 14 days.

The $\mathrm{Ca}(\mathrm{OH})_{2}$ and TAP were placed into the root canals by the aid of size 30 spiral fillers (Dentsply, Mailer, Ballaigues, Switzerland) and condensed with hand pluggers (Dentsply India Pvt Ltd., Mumbai, India). The CEO was inserted into the root canals using sterile endodontic syringes. Any excess medicament was removed and sterile cotton pellets were put into access cavities. The specimens were then incubated in a microaerophilic environment at $37^{\circ} \mathrm{C}$ for the demarcated contact time defined for each experimental group. The medicaments were removed from the root canals at the defined contact time for each experimental group by means of \# $30 \mathrm{~K}$-files (Mani Inc, Tachigi-ken, Japan) and irrigation with $5 \mathrm{ml}$ of sterile saline. The specimens in groups 7, 8, and 9 were irrigated by $1 \mathrm{ml}$ of $0.5 \%$ citric acid (Merck, Germany) and then by $2 \mathrm{ml}$ of sterile saline to neutralize the $\mathrm{Ca}(\mathrm{OH})_{2}$. Other experimental groups (excluding the control groups) were irrigated again with $2 \mathrm{ml}$ of sterile saline. Microbiological harvests were performed after the allocated time of incubation with medicaments using sterile Gates Glidden drills \# 5 (Mani Inc., Tachigi-ken, Japan). This method of sampling was applied according to previous studies. ${ }^{22,23}$ In order to standardize the collection of dentinal shavings, roots with similar morphology and length were selected. The methods of preparation and sampling were similar for all groups. Each drill was used three times up to $10 \mathrm{~mm}$ of the canal length in 10 seconds. The dentin shavings were collected and transferred into $1 \mathrm{ml}$ of sterile $\mathrm{BHI}$, vortexed for 1 minute, serially diluted to 10-fold (up to five times) in $\mathrm{BHI}$ broth, and subsequently incubated in an anaerobic setting at $37^{\circ} \mathrm{C}$ for 24 hours. Aliquots of $100 \mu \mathrm{l}$ from the suspensions were smeared on $\mathrm{BHI}$ agar plates and then incubated at $37^{\circ} \mathrm{C}$ for 24 hours. Bacterial growth was measured by CFU/ml counts of E. faecalis.

\section{Cytotoxicity Assessment}

The cytotoxicity of the experimental medicaments was tested on L929 mouse fibroblasts using MTT colorimetric assay. In this assay, culture medium and hydrogen peroxide served as negative and positive controls respectively. In short, a certain number of L929 mouse fibroblast cells $\left(10^{4}\right)$ were placed in each well of a 96-well microplate and incubated in a humidified atmosphere of $5 \% \mathrm{CO}_{2}, 95 \%$ air at $37^{\circ} \mathrm{C}$ to reach about $70-90 \%$ confluence. Afterward, $150 \mu$ l of each medicament which previously was incubated at $37^{\circ} \mathrm{C}$ in serum containing media for 24 hours was added to each well. After 24 hours incubation, the medium was removed and the wells were washed twice for 2-3 minutes with $150 \mu$ of phosphate buffer saline. Then, $25 \mu \mathrm{l}$ of the MTT (3-(4,5 Dimethylthiazol2-yl)-2,5-diphenyltetrazolium; Sigma-Aldrich, St Louis, USA) stock solution was transferred into each well and incubated in a humidified atmosphere of $5 \% \mathrm{CO}_{2}, 95 \%$ air for 4 hours at $37^{\circ} \mathrm{C}$. At this stage, a tetrazolium ring was created by selective cleavage of mitochondrial dehydrogenase of viable cells, producing blue/purple formazan crystals. After dissolving the formazan, the solution absorption was recorded at a wavelength of $570 \mathrm{~nm}$ by an Elisa plate reader (Model 50, Bio-Rad Corp, Hercules, California, USA). All experiments were performed in triplicate. The cell viability was considered as the percentage of mean optical density values of each medicament compared with the optical density value of the negative control.

\section{Statistical Analysis}

The findings obtained from the first phase of this study were presented descriptively. One-way analysis of variance (ANOVA) / Tukey tests were employed to assess the differences in the zones of inhibition induced by each medicament. One-way ANOVA/least significant difference tests were adopted to compare the bactericidal efficiency of the tested medicaments against planktonic E. faecalis at the designated contact times. To interpret the antibacterial activity of the medicaments against E. faecalis in contaminated root canals, the results were first subjected to logarithmic transformation and expressed as transformed colony forming unit (TCFU) $=\log _{10}$ 
Antimicrobial and Cytotoxic Activity of the Medicaments

$(C F U+1)$. Then, the percentage of reduction in each sample for each time interval was calculated as $\left(\mathrm{TCFU}_{\mathrm{f}}\right.$ $\mathrm{TCFU}_{\mathrm{i}}$ ) $/ \mathrm{TCFU}_{\mathrm{i}} \times 100$, in which $\mathrm{TCFU}_{\mathrm{i}}$ is the initial value and $\mathrm{TCFU}_{\mathrm{f}}$ is the ultimate value. The percentages of reductions were then compared and scrutinized. Because of the violation of normality assumption, nonparametric Kruskal-Wallis $\mathrm{H}$ and Mann-Whitney U tests were employed. The significance level was set at 0.05 . In case of pair-wise comparisons, the significance level was adjusted regarding to the number of comparisons.

One-way ANOVA/Tukey tests were used to assess any differences in the mean cell viability values of the investigational medicaments. All analyses were performed using Statistical Package for the Social Sciences (SPSS) 15.0 software (SPSS Inc., Chicago, IL, USA).

\section{RESULTS}

\section{Chemical Composition of the Essential Oil}

The results of GC-MS analysis of the oil are summarized in Table 1. Eight compounds were recognized, expressing $100 \%$ of the total oil. The major compound was

Table 1: Composition of Cinnamomum zeylanicum essential oil

\begin{tabular}{llll}
\hline Number & Component & Area \% & KI \\
\hline 1 & Cinnamaldehyde, (E) & 0.81 & 1222.581 \\
2 & Cinnamaldehyde, (E) & 77.19 & 1288.729 \\
3 & $\alpha$-Copaene & 8.47 & 1383.158 \\
4 & $\alpha$-Amorphene & 1.31 & 1482.229 \\
5 & $\alpha$-Muurolene & 3.61 & 1506.471 \\
6 & $\delta$-Cadinene & 5.75 & 1530.524 \\
7 & Para-Methoxy cinnamic & 2.03 & 1535.249 \\
& aldehyde & & \\
8 & t-cadinol & 0.83 & 1648.545 \\
\hline & Total identified & 100 &
\end{tabular}

The compounds have been sorted according to retention indices on HP-5 mass spectrometry capillary column; KI: Kováts retention indices
(E)-cinnamaldehyde $(77.19 \%)$, while the minor compounds were $\alpha$-Copaene $(8.47 \%), \delta$-cadinene $(5.75 \%)$, $\alpha$-muurolene $(3.61 \%)$ and para-methoxycinnamic aldehyde (2.04\%).

\section{Comparisons of the Zones of Inhibition, MICs and the MBCs}

Sterile water and PEG 400 did not induce an inhibition zone against $E$. faecalis. One-way ANOVA and Tukey tests revealed that there was a significant difference among the groups. Triple antibiotic paste showed the greatest zone of inhibition among the medicaments tested followed by $\mathrm{CEO}$ and $\mathrm{Ca}(\mathrm{OH})_{2}$. The MIC for TAP, CEO, and $\mathrm{Ca}(\mathrm{OH})_{2}$ was $0.001,0.01$, and $0.1 \mathrm{mg} / \mathrm{ml}$ respectively. The smallest value of MBC was for TAP and it was achieved at a higher dilution than that for $\mathrm{CEO}$ and $\mathrm{Ca}(\mathrm{OH})_{2}$. The results are summarized in Table 2.

\section{Time-kill Assay}

The results are summarized in Table 3. The killing efficacy of the tested medicaments was time dependent. Triple antibiotic paste and CEO totally inhibited the growth of planktonic E. faecalis after 4 and 24 hours respectively. $\mathrm{Ca}(\mathrm{OH})_{2}$ could not achieve $100 \%$ killing even after 24 hours of contact time. Sterile water resulted in a slight increase in the growth of E. faecalis after 4 hours and then it decreased after 24 hours.

\section{Microbial Root Canal Sampling at the Allocated Contact Time}

The bacterial contamination with E. faecalis was confirmed in all root canals at the initial sampling. One-way ANOVA test showed no statistically significant difference between TCFU / $\mathrm{ml}$ counts of all groups at the initial sampling step. The specimens in the positive control groups

Table 2: Results of the disk diffusion and microdilution methods for evaluation of the antibacterial activity against planktonic Enterococcus faecalis

\begin{tabular}{|c|c|c|c|c|c|c|c|c|c|c|c|c|}
\hline & \multicolumn{3}{|c|}{ Cinnamomum zeylanicum } & \multicolumn{3}{|c|}{ Triple antibiotic paste } & \multicolumn{3}{|l|}{$\mathrm{Ca}(\mathrm{OH})_{2}$} & \multicolumn{3}{|l|}{ Ampicillin } \\
\hline ests & DD & MIC & MBC & DD & MIC & MBC & DD & MIC & MBC & DD & MIC & MBC \\
\hline Results & $25.0 \pm 1.8^{a}$ & 0.01 & 0.1 & $37.0 \pm 2.3^{b}$ & 0.001 & 0.01 & $11.0 \pm 4.0^{\mathrm{C}}$ & 0.1 & 1 & $20.0 \pm 3.0^{\mathrm{a}}$ & 0.01 & 0.1 \\
\hline
\end{tabular}

In the disk diffusion (DD) method, the mean zones of inhibition are in $\mathrm{mm}$ including the disk diameter of $6 \mathrm{~mm}$. Equal letters denote a lack of statistically significant difference $(p>0.05)$. The values for minimum inhibitory concentration (MIC) and minimum bactericidal concentration $(\mathrm{MBC})$ are given as $\mathrm{mg} / \mathrm{ml}$. The initial concentration of all medicaments was similar $(1 \mathrm{mg} / \mathrm{ml}$ in dilution 1:1).

Table 3: Number of Enterococcus faecalis colonies (mean \pm SD of CFUs/ml) after 1, 4, and 24 hours of contact time with each medicament

\begin{tabular}{llll}
\hline Medicaments/time & 1 hour & 4 hours & 24 hours \\
\hline Cinnamomum zeylanicum & $6.12 \pm 0.22 \times 10^{6 \mathrm{a}}$ & $3.41 \pm 0.65 \times 10^{3 \mathrm{~b}}$ & $0^{\mathrm{c}}$ \\
Triple antibiotic paste & $2.34 \pm 0.09 \times 10^{1 \mathrm{a}}$ & $0^{\mathrm{b}}$ & $0^{\mathrm{b}}$ \\
$\mathrm{Ca}(\mathrm{OH})_{2}$ & $9.47 \pm 0.10 \times 10^{7 \mathrm{a}}$ & $7.21 \pm 0.98 \times 10^{5 \mathrm{~b}}$ & $6.11 \pm 0.00 \times 10^{2 \mathrm{c}}$ \\
Negative control (sterile water) & $1.11 \pm 0.05 \times 10^{8 \mathrm{a}}$ & $1.26 \pm 0.65 \times 10^{8 \mathrm{a}}$ & $1.31 \pm 0.24 \times 10^{8 \mathrm{a}}$ \\
\hline
\end{tabular}

The initial amount of bacteria was equal to $0.5 \mathrm{McF}$ arland standard $\left(1.5 \times 10^{8} \mathrm{CFU}\right)$. Read horizontally, equal letters denote a lack of statistically significant difference ( $p>0.05$ ); CFU: colony-forming units 
Table 4: The median (mean \pm SD) percentage reduction of the transformed CFU/ml

\begin{tabular}{llll}
\hline & 1 day & 7 days & 14 days \\
\hline Cinnamomum zeylanicum & $31.44 \%(32.18 \pm 5.18)^{\mathrm{A}, \mathrm{a}}$ & $100.00 \%(92.96 \pm 13.57)^{\mathrm{A}, \mathrm{b}}$ & $100.00 \%(100.00 \pm 0.00)^{\mathrm{A}, \mathrm{b}}$ \\
Triple antibiotic paste & $30.42 \%(30.06 \pm 2.30)^{\mathrm{A}, \mathrm{a}}$ & $96.20 \%(84.60 \pm 18.72)^{\mathrm{A}, \mathrm{b}}$ & $100.00 \%(98.83 \pm 2.50)^{\mathrm{A}, \mathrm{b}}$ \\
$\mathrm{Ca}(\mathrm{OH})_{2}$ & $24.55 \%(26.83 \pm 6.29)^{\mathrm{A}, \mathrm{a}}$ & $51.71 \%(53.60 \pm 17.46)^{\mathrm{B}, \mathrm{b}}$ & $89.66 \%(84.36 \pm 18.08)^{\mathrm{B}, \mathrm{c}}$ \\
Positive control & $2.75 \%(1.93 \pm 1.64)^{\mathrm{B}, \mathrm{a}}$ & $2.00 \%(2.33 \pm 1.52)^{\mathrm{C}, \mathrm{a}}$ & $3.01 \%(3.01 \pm 1.00)^{\mathrm{C}, \mathrm{a}}$ \\
\hline
\end{tabular}

Read vertically, uppercase letters denote comparisons between groups at each defined contact time (adjusted $\alpha=0.0083$ ). Read horizontally, lowercase letters denote comparisons between the defined contact times in each group (adjusted $\alpha=0.017$ ). Equal letters denote a lack of statistically significant difference $(p>\alpha)$. SD: Standard deviation; CFU: Colony-forming units

showed similar TCFU/ml counts for all three sampling steps with no statistical differences. The specimens in the negative control groups confirmed the absence of microbial growth at all three contact times. The results showed that the TCFU / $\mathrm{ml}$ counts decreased from the initial counts for all three tested medicaments. The percentage reduction of TCFU $/ \mathrm{ml}$ counts significantly increased in all groups by extending the contact time. After the first day of incubation, the increase in TCFU/ $\mathrm{ml}$ count reduction was statistically significant for the three tested medicaments. The bacterial load reduction from 7 to 14 days of incubation was significant for $\mathrm{Ca}(\mathrm{OH})_{2}$ but not significant for TAP and CEO. No statistically significant difference was detected between the medicaments after 1 day of incubation, but a significant difference was detected after 7 and 14 days. The results are summarized in Table 4 .

\section{Cytotoxicity Assessment}

Graph 1 displays the mean cell viability (\%) of L929 fibroblasts in each experimental group. One-way ANOVA/ Tukey tests showed a statistically significant difference between the groups; $35 \% \mathrm{H}_{2} \mathrm{O}_{2}$ as positive control caused $98.58 \%$ cell death. Cinnamomum zeylanicum essential oil was the most cytocompatible medicament to L929 fibroblasts. There was no statistically significant difference between cytotoxicity of TAP and $\mathrm{Ca}(\mathrm{OH})_{2}$.

\section{DISCUSSION}

Plant essential oils are potential sources of new antimicrobial compounds especially against bacterial pathogens. These essential oils have hydrophobicity characteristics. Therefore, they can affect interfacial tension in the lipids of the bacterial cell wall and the mitochondria and subsequently destroy the bacterial structures. ${ }^{16}$

The current research was performed to investigate the potential of using $\mathrm{CEO}$ as an intracanal dressing during root canal treatment. The chemical components of CEO were determined to avoid the lack of standardization and also to have a better understanding of its bioactivity.

Cinnamaldehyde was the major component of CEO. Consistent with these findings, other researchers have found cinnamaldehyde to be a major component

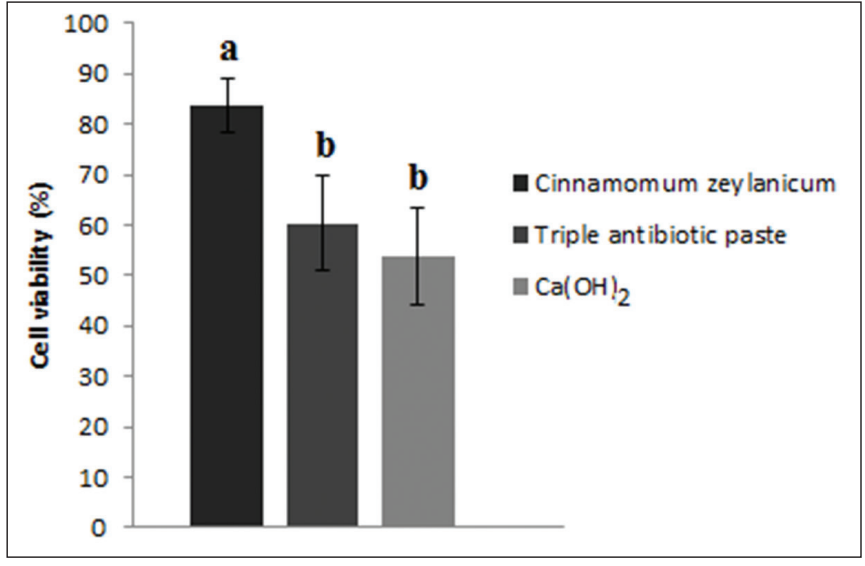

Graph 1: Mean viability (\%) of L929 fibroblast cells after 24-hour contact with the medicaments. Equal letters denotes a lack of statistically significant difference $(p>0.05)$

(44.2-97.7\%) of cinnamon bark oil, ${ }^{16,24,25}$ and they reported that it has excellent antibacterial ${ }^{25}$ and sedative properties. ${ }^{26}$ Cinnamaldehyde with the chemical formula of an aldehyde $\left(\mathrm{C}_{9} \mathrm{H}_{8} \mathrm{O}\right)$ has low acute toxicity to mammals and gives cinnamon its flavor and odor. ${ }^{27}$

In the second part of this study, the antibacterial performance of $C E O$ was assessed against $E$. faecalis as the most challenging organism in root canal treatment and this was compared with that of $\mathrm{Ca}(\mathrm{OH})_{2}$ and TAP as the two most frequently used root canal dressing materials in endodontics. The cytotoxicity of these medicaments was also compared and evaluated.

The main idea of this study was adopted from previous studies, which confirmed the antibacterial effectiveness of C. zeylanicum against planktonic and biofilm E. faecalis. ${ }^{7,19}$ In the current study, the hypothesis regarding the antibacterial and cytotoxic activity of CEO was not confirmed.

The results were partially confirmatory and in line with the findings achieved by a recent preliminary study by Gupta et al. ${ }^{7}$ In their study, the effectiveness of C. zeylanicum extract against $E$. faecalis was investigated, and they found that this extract could completely inhibit the growth of both the planktonic and biofilm forms of E. faecalis after 30 minutes and 12 hours respectively. As a result, they proposed that this herb could be used as an intracanal medicament rather than as an irrigating 
solution. In the current experiment, this plant essential oil was evaluated as a root canal dressing material. Its time-dependent bactericidal activity against planktonic and biofilm $E$. faecalis was investigated and compared with that of $\mathrm{Ca}(\mathrm{OH})_{2}$ and TAP.

Although CEO initially presented a lower antibacterial activity than TAP against planktonic E. faecalis, this effect increased gradually by extending the contact time and became equal after 24 hours. Further, CEO exhibited a comparable bactericidal effect to TAP against biofilm E. faecalis, although the results were time dependent. The percentage of bacterial reduction after intracanal application of the three tested medicaments was similar after 1 day. However, after 7 days, CEO and TAP demonstrated significantly more reduction. Finally, after 14 days, both CEO and TAP completely eliminated E. faecalis. These findings depicted the slow-acting nature of this medicinal plant. This study also revealed that bacterial reduction in 7-day intracanal application of these two medicaments was not statistically different from their 14-day application.

$\mathrm{Ca}(\mathrm{OH})_{2}$ had a lower efficacy against both planktonic and biofilm forms of E. faecalis compared with the other two tested medicaments. Extending the intracanal medication with $\mathrm{Ca}(\mathrm{OH})_{2}$ resulted in significantly enhanced bacterial reduction. However, it could not completely eradicate E. faecalis even after 14 days. In contrast with the current study, Behnen et $\mathrm{al}^{28}$ showed that $\mathrm{Ca}(\mathrm{OH})_{2}$ could eliminate E. faecalis after 1 day, while Sjögren et $\mathrm{al}^{29}$ and Shuping et a ${ }^{30}$ reported the same effect after 7 days. The possible reason for these inconsistencies might be due to the different methods of evaluation.

Some researchers have reported that $\mathrm{Ca}(\mathrm{OH})_{2}$ should be left in the root canals for more than 14 days to be effective when used in infected teeth. ${ }^{31,32}$ The relatively low effectiveness against $E$. faecalis, which was also experienced in this study, might be explained by the possible potential of this microorganism to resist alkaline changes. ${ }^{33,34}$ This impaired effect can also be attributed to the buffering action of dentin ${ }^{35}$ or the relatively low amount of hydroxyl ions released from $\mathrm{Ca}(\mathrm{OH})_{2}$ to inhibit dentinal biofilm. ${ }^{36}$

When the effectiveness of $\mathrm{Ca}(\mathrm{OH})_{2}$ and TAP was compared, the bacterial reduction in the biofilm model obtained by these medicaments was not statistically different after 1 day, but TAP exhibited significantly higher reduction after 7 and 14 days.

Triple antibiotic paste was found to be more effective than $\mathrm{Ca}(\mathrm{OH})_{2}$ against E. faecalis in a recent study that evaluated these medicaments against the formation of E. faecalis biofilm after 1, 2, and 3-day intervals. ${ }^{37}$ Likewise, other investigations have also reported that TAP was more efficient than $\mathrm{Ca}(\mathrm{OH})_{2}$ in eliminating E. faecalis in infected root canals after 7 days. ${ }^{36,38}$ Although the findings of the current study revealed that extending the contact time for $\mathrm{Ca}(\mathrm{OH})_{2}$ and TAP resulted in an enhanced antimicrobial activity, this extended contact time may increase the possible risk of change in dentin structure or dentin discoloration. ${ }^{39,40}$

The reason for selecting E. faecalis in this experiment is that this bacterium is considered as a possible source of persistent infections following root canal treatment. ${ }^{41}$ In this study, in order to simulate the clinical conditions, human permanent teeth were contaminated with this bacterium. To allow the bacteria to completely diffuse into the dentinal tubules, the smear layer was removed and then a 21-day incubation period was selected to allow a mature biofilm to form. ${ }^{42}$

In the present study, an immortalized L929 cell line was employed to compare the cytotoxicity of the experimental medicaments. This cell line was preferred since it is a well-exemplified cell model and has been previously engaged in evaluation of the cytotoxic effects of dental materials. ${ }^{43,44}$ The results showed that CEO only produced a small $(16 \%)$ decrease in cell viability, while this value was more than 46 and $40 \%$ for $\mathrm{Ca}(\mathrm{OH})_{2}$ and TAP respectively. Such reasonable level of cytotoxicity against mouse primary fibroblasts has also been previously reported for aqueous cinnamomum extract. ${ }^{45}$

The cytotoxicity of TAP and $\mathrm{Ca}(\mathrm{OH})_{2}$ on the viability of L929 fibroblasts was found to be similar. This was not consistent with another study performed on $\mathrm{Ca}(\mathrm{OH})_{2}, \mathrm{TAP}$, double antibiotic paste, and minocycline, which showed that $\mathrm{Ca}(\mathrm{OH})_{2}$ had a lower effect on cell viability of periodontal ligament fibroblasts and the expression of proinflammatory cytokines than other tested medicaments. ${ }^{46}$ The inconsistency between the results can be due to the difference in cellular particle uptake of different cell types.

The use of antimicrobial intracanal medicaments with good biocompatibility may result in elimination of the remained organisms in root canal system and increase the rate of favorable outcomes of root canal treatment. ${ }^{47}$ Although the results of the current study support that CEO could be an effective and biocompatible antibacterial agent due to the presence of a high level of cinnamaldehyde in its composition, it is noteworthy that possible interactions between chemical, physical, and pharmacological properties of this oil with the root canal filling materials are still unclear. Therefore, a conclusive comment on its application in root canal treatment should not be made until further evaluations have been performed on animal or human models.

\section{CONCLUSION}

Under the conditions of this study, CEO exhibited a strong antimicrobial efficiency against planktonic and biofilm E. faecalis and it was biocompatible to L929 fibroblasts. 


\section{ACKNOWLEDGMENTS}

This article has been extracted from Mrs Dadolahi's DDS thesis. The study was approved, registered with ID \# 8692008, and supported by the International Branch of Shiraz University of Medical Sciences. The authors would also like to thank Dr S Sobhani and Dr M Vosooghi for their valuable comments to improve the quality of the article.

\section{REFERENCES}

1. Bakkali F, Averbeck S, Averbeck D, Idaomar M. Biological effects of essential oils-a review. Food Chem Toxicol 2008 Feb;46(2):446-475.

2. Ríos J, Recio M. Medicinal plants and antimicrobial activity. J Ethnopharmacol 2005 Aug22;100(1-2):80-84.

3. Gentil M, Pereira JV, Sousa YT, Pietro R, Neto MD, Vansan LP, de Castro França S. In vitro evaluation of the antibacterial activity of Arctium lappa as a phytotherapeutic agent used in intracanal dressings. Phytother Res 2006 Mar;20(3):184-186.

4. Murray PE, Farber RM, Namerow KN, Kuttler S, GarciaGodoy F. Evaluation of Morinda citrifolia as an endodontic irrigant. J Endod 2008 Jan;34(1):66-70.

5. Prabhakar J, Senthilkumar M, Priya MS, Mahalakshmi K, Sehgal PK, Sukumaran VG. Evaluation of antimicrobial efficacy of herbal alternatives (Triphala and green tea polyphenols), MTAD, and 5\% sodium hypochlorite against Enterococcus faecalis biofilm formed on tooth substrate: an in vitro study. J Endod 2010 Jan;36(1):83-86.

6. Badr AE, Omar N, Badria FA. A laboratory evaluation of the antibacterial and cytotoxic effect of Liquorice when used as root canal medicament. Int Endod J 2011 Jan;44(1):51-58.

7. Gupta A, Duhan J, Tewari S, Sangwan P, Yadav A, Singh G, Juneja R, Saini H. Comparative evaluation of antimicrobial efficacy of Syzygium aromaticum, Ocimum sanctum and Cinnamomum zeylanicum plant extracts against Enterococcus faecalis: a preliminary study. Int Endod J 2013 Aug;46(8):775-783.

8. Abbaszadegan A, Sahebi S, Gholami A, Delroba A, Kiani A, Iraji A, Abbott PV. Time-dependent antibacterial effects of Aloe vera and Zataria multiflora plant essential oils compared to calcium hydroxide in teeth infected with Enterococcus faecalis. J Investig Clin Dent 2016 Feb;7(1):93-101.

9. Nabavizadeh M, Abbaszadegan A, Gholami A, Sheikhiani R, Shokouhi M, Shams MS, Ghasemi Y. Chemical constituent and antimicrobial effect of essential oil from Myrtus communis leaves on microorganisms involved in persistent endodontic infection compared to two common endodontic irrigants: an in vitro study. J Conserv Dent 2014 Sep;17(5):449-453.

10. Abbaszadegan A, Gholami A, Mirhadi H, Saliminasab M, Kazemi A, Moein MR. Antimicrobial and cytotoxic activity of Ferula gummosa plant essential oil compared to $\mathrm{NaOCl}$ and CHX: a preliminary in vitro study. Restor Dent Endod 2015 Feb;40(1):50-57.

11. Abbaszadegan A, Gholami A, Ghahramani Y, Ghareghan R, Ghareghan M, Kazemi A, Iraji A, Ghasemi Y. Antimicrobial and cytotoxic activity of Cuminum cyminum as an intracanal medicament compared to chlorhexidine gel. Iran Endod J 2016 Winter;11(1):44-50.

12. World Health Organization (WHO). Cortex Cinnamomi. WHO monographs on selected medicinal plants, Geneva. Vol 11999. p. 95-104.
13. Jayaprakasha GK, Rao LJ. Chemistry, biogenesis, and biological activities of Cinnamomum zeylanicum. Crit Rev Food Sci Nutr 2011 Jul;51(6):547-562.

14. Sangal A. Role of cinnamon as beneficial antidiabetic food adjunct: a review. Adv App Sci Res 2011;2(4):440-450.

15. Wijesekera R, Jayewardene A, Rajapakse LS. Volatile constituents of leaf, stem and root oils of cinnamon (Cinnamomum zeylanicum). J Sci Food Agric 1974 Oct;25(10):1211-1220.

16. Cowan MM. Plant products as antimicrobial agents. Clin Microbiol Rev 1999 Oct;12(4):564-582.

17. Nir Y, Potasman I, Stermer E, Tabak M, Neeman I. Controlled trial of the effect of cinnamon extract on Helicobacter pylori. Helicobacter 2000 Jun;5(2):94-97.

18. Lopez P, Sanchez C, Batlle R, Nerin C. Solid- and vapor-phase antimicrobial activities of six essential oils: susceptibility of selected foodborne bacterial and fungal strains. J Agric Food Chem 2005 Aug 24;53(17):6939-6946.

19. Khan R, Islam B, Akram M, Shakil S, Ahmad A, Ali SM, Siddiqui M, Khan AU. Antimicrobial activity of five herbal extracts against multi drug resistant (MDR) strains of bacteria and fungus of clinical origin. Molecules 2009 Feb 4; 14(2):586-597.

20. Zalipsky S. Chemistry of polyethylene glycol conjugates with biologically active molecules. Adv Drug Deliv Rev 1995 Sep;16(2-3):157-182.

21. Clinical and Laboratory Standards Institute (CLSI). Performance standards for antimicrobial disk susceptibility tests; approved standard. 11th ed. CLSI document M02-A11. Wayne, PA: National Committee for Clinical Laboratory Standards; 2008.

22. Javidi M, Afkhami F, Zarei M, Ghazvini K, Rajabi O. Efficacy of a combined nanoparticulate/calcium hydroxide root canal medication on elimination of Enterococcus faecalis. Aust Endod J 2014 Aug;40(2):61-65.

23. Delgado RJ, Gasparoto TH, Sipert CR, Pinheiro CR, de Moraes IG, Garcia RB, Duarte MA, Bramante CM, Torres SA, Garlet GP, et al. Antimicrobial activity of calcium hydroxide and chlorhexidine on intratubular Candida albicans. Int J Oral Sci 2013 Mar;5(1):32-36.

24. Simic A, Sokovic MD, Ristic M, Grujic-Jovanovic S, Vukojevic J, Marin PD. The chemical composition of some Lauraceae essential oils and their antifungal activities. Phytother Res 2004 Sep;18(9):713-717.

25. Senanayake UM, Lee TH, Wills RB. Volatile constituents of cinnamon (Cinnamomum zeylanicum) oils. J Agric Food Chem 1978 Jul;26(4):822-824.

26. Watanabe H, Hagiwara M, Tohda M, Hiyama Y, Terasawa K, Watanabe K. Central effects of cinnamaldehyde. Yakugaku Zasshi 1984 Oct;104(10):1095-1100.

27. Stammati A, Bonsi P, Zucco F, Moezelaar R, Alakomi HL, von Wright A. Toxicity of selected plant volatiles in microbial and mammalian short-term assays. Food Chem Toxicol 1999 Aug;37(8):813-823.

28. Behnen MJ, West LA, Liewehr FR, Buxton TB, McPherson JC. Antimicrobial activity of several calcium hydroxide preparations in root canal dentin. J Endod 2001 Dec;27(12): 765-767.

29. Sjögren U, Figdor D, Spångberg L, Sundqvist G. The antimicrobial effect of calcium hydroxide as a short-term intracanal dressing. Int Endod J 1991 May;24(3):119-125.

30. Shuping GB, Orstavik D, Sigurdsson A, Trope M. Reduction of intracanal bacteria using nickel-titanium rotary 
instrumentation and various medications. J Endod 2000 Dec;26(12):751-755.

31. Nerwich A, Figdor D, Messer HH. pH changes in root dentin over a 4-week period following root canal dressing with calcium hydroxide. J Endod 1993 Jun;19(6):302-306.

32. LeonardoMR,SilveiraFF,Silva LA, TanomaruFilhoM,Utrilla LS. Calcium hydroxide root canal dressing. Histopathological evaluation of periapical repair at different time periods. Braz Dent J 2002 Jan;13(1):17-22.

33. Chavez de Paz LE, Bergenholtz G, Dahlen G, Svensater G. Response to alkaline stress by root canal bacteria in biofilms. Int Endod J 2007 May;40(5):344-355.

34. Brandle N, Zehnder M, Weiger R, Waltimo T. Impact of growth conditions on susceptibility of five microbial species to alkaline stress. J Endod 2008 May;34(5):579-582.

35. Haapasalo H, Sirén E, Waltimo T, Orstavik D, Haapasalo M. Inactivation of local root canal medicaments by dentine: an in vitro study. Int Endod J 2000 Mar;33(2):126-131.

36. Ordinola-Zapata R, Bramante CM, Minotti PG, Cavenago BC, Garcia RB, Bernardineli N, Jaramillo DE, Hungaro Duarte MA. Antimicrobial activity of triantibiotic paste, $2 \%$ chlorhexidine gel, and calcium hydroxide on an intraoral-infected dentin biofilm model. J Endod 2013 Jan;39(1):115-118.

37. Sabrah AH, Yassen GH, Gregory RL. Effectiveness of antibiotic medicaments against biofilm formation of Enterococcus faecalis and Porphyromonas gingivalis.J Endod 2013 Nov;39(11):1385-1389.

38. Madhubala MM, Srinivasan N, Ahamed S. Comparative evaluation of propolis and triantibiotic mixture as an intracanal medicament against Enterococcus faecalis. J Endod 2011 Sep;37(9):1287-1289.

39. Sahebi S, Moazami F, Abbott P. The effects of short-term calcium hydroxide application on the strength of dentine. Dent Traumatol 2010 Feb;26(1):43-46.
40. Kim JH, Kim Y, Shin SJ, Park JW, Jung IY. Tooth discoloration of immature permanent incisor associated with triple antibiotic therapy: a case report. J Endod 2010 Jun;36(6):1086-1091.

41. Stuart CH, Schwartz SA, Beeson TJ, Owatz CB. Enterococcus faecalis: its role in root canal treatment failure and current concepts in retreatment. J Endod 2006 Feb;32(2):93-98.

42. Heling I, Steinberg D, Kenig S, Gavrilovich I, Sela MN, Friedman M. Efficacy of a sustained-release device containing chlorhexidine and $\mathrm{Ca}(\mathrm{OH})_{2}$ in preventing secondary infection of dentinal tubules. Int Endod J 1992 Jan;25(1):20-24.

43. Mirhadi H, Abbaszadegan A, Ranjbar MA, Azar MR, Geramizadeh B, Torabi S, Sadat Aleyasin Z, Gholami A. Antibacterial and toxic effect of hydrogen peroxide combined with different concentrations of chlorhexidine in comparison with sodium hypochlorite. J Dent (Shiraz) 2015 Dec;16(4):349-355.

44. Abbaszadegan A, Nabavizadeh M, Gholami A, Aleyasin ZS, Dorostkar S, Saliminasab M, Ghasemi Y, Hemmateenejad B, Sharghi H. Positively charged imidazolium-based ionic liquidprotected silver nanoparticles: a promising disinfectant in root canal treatment. Int Endod J 2015 Aug;48(8):790-800.

45. Singh R, Koppikar SJ, Paul P, Gilda S, Paradkar AR, KaulGhanekar R. Comparative analysis of cytotoxic effect of aqueous cinnamon extract from Cinnamomum zeylanicum bark with commercial cinnamaldehyde on various cell lines. Pharm Biol 2009 Nov;47(12):1174-1179.

46. Yadlapati M, Souza LC, Dorn S, Garlet GP, Letra A, Silva RM. Deleterious effect of triple antibiotic paste on human periodontal ligament fibroblasts. Int Endod J 2014 Aug;47(8):769-775.

47. Byström A, Claesson R, Sundqvist G. The antibacterial effect of camphorated paramonochlorophenol, camphorated phenol and calcium hydroxide in the treatment of infected root canals. Endod Dent Traumatol 1985 Oct;1(5):170-175. 